\title{
The Evanston Colloquium
}

\section{Lectures on Mathematics}

Delivered from Aug. 28 to Sept. 9, 1893, before members of the Congress of Mathematics held in connection with the World'g Fair in Chicago at Northwestern University, Evanston, Ill.

\section{By FELIX KLEIN}

Reported by Alexander Ziwet. Republished by the American Mathematical Society, New York, 1911.

Professor Klein's Evanston Colloquium Lectures on Mathematics, which have for some years been out of print, have been republished by the American Mathematical Society and are now on sale at the nominal price of seventy-five cents per copy. The new edition is printed from the original plates, with correction of a few misprints. A brief preface by Professor W. F. Osgood has been added. The volumes are bound like the original. Orders should be addressed to the

\section{AMERICAN MATHEMATICAL SOCIETY \\ 501 West 116th Street, New York, N. Y.}




\section{Whole No. 211}

\section{CONTENTS}

Surfaces of Revolution of Minimum Resistance. By Dr. E.

$\begin{array}{cccccccccc}\text { J. Mrles } & - & - & - & - & - & - & - & - & -1 \\ \text { Shorter Notices } & - & - & - & - & - & - & - & - & -12 \\ \text { Notes - - } & - & - & - & - & - & - & - & - & -33 \\ \text { New Publications - } & - & - & - & - & - & - & - & -44\end{array}$

Changes of address of members, exchanges, and subscribers should be communicated at once to the Secretary of the American Mathematical Society, 501 West 116th Street, New York.

Subscriptions to the BuLLETIN, orders for back numbers, and inquiries in regard to non-delivery of current numbers should be addressed to The American Mathematical Society, 41 North Queen St., Lancaster, Pa., or 501 West 116th Street, New York.

The initiation fees and annual dues of members of the American Mathematioal Society are payable to the Treasurer of the American Mathematical Sooiety, Professor J. H. Tanner, Cornell Heights, Ithaca, N. Y.

Articles for insertion in the BuLLETIN should be addressed to the Bulletin of the American Mathematical Society, 501 West 116th Street, New York City.

The following dates have been fixed for the meetings of the Society :

$$
\text { A. M. A. M. }
$$

Sat., Oct. 26, 1912, 11:00 Sat., Feb. 22, 1913, 11:00

Deo. 31, 1912-Jan. 2, $1913 . \quad$ Sat., Apr. 26, " “

The regular metting of the San Francisco Section will be held at the University of California on Saturday, October 26.

The Southwestern Section will meet at the University of Kansas, on Friday and Saturday, November 29-30.

The Nineteenth Annual Meeting of the Society will be held at Cleveland, Ohio, T'uesday-Thursday, December 31-January 2.

THE NEW ERA PRINT, LANGAGTER PA, 